\title{
A critical look at mass balance constraints of sedimentary carbonates
}

\section{CLARA BLÄTTLER}

\section{University of Chicago}

Presenting Author: cblattler@uchicago.edu

In studies of ancient rocks on Earth, it is regularly assumed that the materials available for sampling and analysis are representative of what existed on a global scale. The extent of survivorship bias - what unusual properties may be present in existing rocks, and ultimately related to their availability on Earth's surface today - is rarely acknowledged and often challenging to test. This question of representativeness is separate from, but equally important to, that of preservation; if this bias is important, critical interpretations about global geochemical cycles based on small amounts of preserved rock of a given age may need to be reassessed.

Marine carbonate sediments are the source of many canonical geochemical records shaping our understanding of surface environments and the carbon cycle over billions of years. For example, the carbon isotope mass balance equation $\left[\delta^{13} \mathrm{C}_{\text {mantle }}=\right.$ $\left.f_{\text {org }} \cdot \delta^{13} \mathrm{C}_{\text {organic } \mathrm{C}}+\left(1-f_{\text {org }}\right) \cdot \delta^{13} \mathrm{C}_{\text {carbonate }}\right]$ forms the basis for many interpretations of organic and inorganic carbon cycling as well as surface oxygenation. Thanks to the coupling of elemental cycles within the sedimentary carbonate reservoir, the calcium isotope mass balance can be used to test the representativeness of the carbonate carbon isotope record and thus address survivorship bias within this key archive [1]. Additionally, calcium isotope ratios can be useful for identifying distinct components of these sedimentary carbon sinks, including diagenetic or authigenic carbonates, that may escape petrographic identification after burial and metamorphic recrystallization. These sedimentary components can skew the carbon isotope mass balance, burying isotopically anomalous carbon that may be decoupled from contemporaneous seawater or exert a different impact on the global redox budget. A series of recent case studies suggests that the classical carbon isotope mass balance equation may only rarely be appropriate for interpreting the global carbon cycle or surface oxidation.

[1] Blättler \& Higgins (2017), Earth and Planetary Science Letters 479, 241-251. 